\title{
Citizen Science and the Role in Sustainable Development
}

\author{
Daniel Dörler ${ }^{1, *(\mathbb{C}}$, Steffen Fritz ${ }^{2}$, Silke Voigt-Heucke ${ }^{3}$ and Florian Heigl ${ }^{1}[\mathbb{D}$ \\ 1 Institute of Zoology, University of Natural Resources and Life Sciences Vienna, Gregor Mendel Straße 33, \\ 1180 Vienna, Austria; florian.heigl@boku.ac.at \\ 2 International Institute for Applied Systems Analysis, A-2361 Laxenburg, Austria; fritz@iiasa.ac.at \\ 3 Museum für Naturkunde Berlin, Leibniz Institute for Evolution and Biodiversity Science, Invalidenstraße 43, \\ 10115 Berlin, Germany; Silke.Voigt-Heucke@mfn.berlin \\ * Correspondence: daniel.doerler@boku.ac.at
}

check for updates

Citation: Dörler, D.; Fritz, S.; Voigt-Heucke, S.; Heigl, F. Citizen Science and the Role in Sustainable Development. Sustainability 2021, 13, 5676. https://doi.org/10.3390/ su13105676

Received: 1 May 2021

Accepted: 14 May 2021

Published: 19 May 2021

Publisher's Note: MDPI stays neutral with regard to jurisdictional claims in published maps and institutional affiliations.

Copyright: (c) 2021 by the authors. Licensee MDPI, Basel, Switzerland. This article is an open access article distributed under the terms and conditions of the Creative Commons Attribution (CC BY) license (https:// creativecommons.org/licenses/by/ $4.0 /)$.
Citizen science (cs) has manifold potential in generating new knowledge, raising awareness and enabling learning, as numerous studies have shown in recent years [1]. The Stockholm Environment Institute published a discussion brief [2] already in 2017 on how cs could contribute to the SDGs, where the potential for cs was identified in contributing to the definition of new targets and metrics, in monitoring progress and in implementing the SDGs. Fritz et al. [3] identified gaps in traditional data sources for monitoring and implementing the United Nations Sustainable Development Goals and showed the potential of cs to fill these gaps. Consequently, Fraisl et al. [4] showed in a systematic review that cs is already contributing to five indicators and could contribute to 76 more indicators. However, the main contribution of cs seems to be focused on SDG 15, 'Life on Land', SDG 11, 'Sustainable Cities and Communities', SDG 3, 'Good Health and Wellbeing' and SDG 6, 'Clean Water' and Sanitation'. In October 2020, the 'Citizen Science SDG Conference: Knowledge for Change: A decade of Citizen Science (2020-2030) in support of the Sustainable Development Goals' illustrated the diversity of cs projects and acted as a forum for reflection and perspectives, with cross-cutting contributions to collectively define the latest developments, impacts, benefits and challenges around the role of cs for the SDGs. Numerous papers published in this Special Issue were contributions to this conference [5].

We are delighted to present in this Special Issue a wide range of papers, including research articles, reviews and commentaries, which explore from different perspectives how cs can contribute to the achievement of the SDGs at local, regional and international levels.

Five articles give an overview of how cs projects can contribute or support the SDGs. For example, cs can play an important role as a mediator to reach the SDGs, as Heinisch wrote in her article. She highlighted the importance of translation and making sure terminologies and a specific language in the field of SDGs and cs are understood. Both need to transfer knowledge and meaning to people outside academia in order to become accessible to the wider public. Heinisch concluded that different types of knowledge are needed to enable the societal transformation that is required to reach the SDGs.

A special form of cs, namely citizen observatories, and its potential to contribute to SDG indicator monitoring or to support SDG targets was the focus of Ajates et al. They found out that in the case of the GROW Observatory, the data collected directly support 4 SDG indicators targets and activities could potentially contribute to 39 targets. The authors concluded that citizen observatories could help not only in contributing to indicator monitoring but that there is an even higher potential in contributing to implementing the SDGs via transformative action on the ground.

To find out how cs projects are already in one way or another contributing to the monitoring or implementation of the SDGs, Schleicher and Schmidt analyzed 127 cs projects which are featured on the German cs platform 'Bürger schaffen Wissen'. They conducted a qualitative content analysis of the different project descriptions and found that 12 of the 
17 SDGs were addressed by at least 1 of the 127 projects and that SDG 15 and SDG 4 were primarily targeted.

Moczek et al. invited cs project teams within Europe to participate in a survey in which they could self-assess their contribution to the SDGs, in which areas of the SDGs they feel they contribute to already or could contribute to in future, and where they felt they would need further assistance. The 125 answers revealed that there is still little knowledge on the relationships between SDGs and cs and that most projects see their contribution in monitoring or raising awareness. The survey also revealed that a majority of teams who participated in the survey require more guidance and assistance on how to make the data and their analysis more relevant and useful for the SDGs.

Sprinks et al. took a qualitative approach and interviewed eleven cs project coordinators in depth to explore how they see their projects' impacts and relations to the SDGs and their indicators. These semi-structured interviews revealed both positive relations in coordinators toward their projects' contributions to the SDGs and critical remarks regarding certain aspects such as objective measures versus subjective judgements. Overall, the study presents a complex and very diverse picture of how project coordinators see their contribution of cs to the different SDGs.

While the previously mentioned five articles give a more general view on how cs can contribute to the SDGs, there is also the potential of a wide contribution on the level of the individual SDG targets and indicators as the following articles elaborate.

Kral et al. investigated on an island in the Java sea together with local farmers how the deeper involvement of citizens could help to contribute toward the goal of Zero Hunger (SDG 2). They conducted a co-experimentation study on the regeneration of degraded soils, which addressed SDGs 2.3 and 2.4. The project team consisted of academic researchers and citizen scientists, i.e., local farmers. Through this transdisciplinary approach, they were able to take into consideration ecological, economic and social aspects. The cs project was able to restore local soil, which led to a significant increase in yield and provided insights into how local stakeholder involvement can be used to develop locally adapted interventions.

Calyx discussed in a commentary how a cs project helped to fight the Ebola crises. She emphasized the importance of open data illustrating that open data not only play a critical role in addressing SDG3 'Good Health and Wellbeing' but also in addressing other SDGs.

Asingizwe et al. focused on another deadly disease in their article: Malaria in Rwanda. An efficient monitoring and control strategy is needed to reduce the risk of Malaria infections. One way to achieve this is to use a cs approach for surveilling mosquitos in human settlements. In their article, Asiginzwe et al. observed that cs is likely to work best when citizens are involved from the start in the selection of technical and social aspects (e.g., who collects what data and how frequently, and what kind of tools are used for the data collection).

How can cs increase scientific literacy in formal education and contribute to 'Quality Education' (SDG 4) at the same time? This question was tackled by Queiruga-Dios et al., who analyzed how a cs project in a school changed the students' attitudes toward science and technology, how it improved their scientific literacy and how it contributed to addressing the SDGs. They recorded a significantly positive change in attitude toward science and technology and scientific literacy of the students after they had contributed to a cs project.

'Clean Water and Sanitation' (SDG 6) are essential parts of a healthy life. Can a cs project, however, be designed to derive a reliable indicator score for SDG indicator 6.3.2? What value does the integration of cs data have for this indicator? Finally, how can the potential benefit of cs for SDG reporting be maximized? These questions were evaluated by Bishop et al. in their study, which took place in England and Zambia. They confirmed that cs can be used to produce a reliable indicator score for indicator 6.3.2 and present recommendations and practical considerations for similar approaches.

One key SDG is 'Affordable and Clean Energy' (SDG 7). Wuebben et al. focused on energy production and investigated the relationship between cs and energy communities 
that often aim to achieve a sustainable energy supply. To understand this relationship, they undertook a systematic literature review and found that there are participatory elements in many energy communities. However, they could not identify an explicit alliance between cs and those energy communities, revealing a huge potential in this area.

Energy consumption, on the other hand, is increasing worldwide, and in many cases, fossil fuels are used to meet these increasing demands. One way to tackle this problem is energy efficiency and reducing energy consumption. However, to reduce energy consumption, it is important to take the perspective and needs of citizens into consideration. In their review study, Filippo et al. systematically investigated if the needs of citizens were accounted for when designing research projects in energy efficiency and consumption. They discovered that only 366 out of more than 230,000 papers that were either dealing with energy efficiency or with cs were combining these two topics.

Climate change is probably one of the biggest challenges that humankind is facing today, and Climate Action (SDG 13) is pertinent. Technology can help to contribute to or raise awareness for the SDGs and especially climate change. Batsaikhan et al. discussed this technological aspect in the context of a recent cs project called BAYSICS in the German federal state of Bavaria, and how its goals are aligning with several SDGs.

Gardening techniques can also impact our climate. To investigate a within-garden effect in garden soils dependent on soil amendments, Duddigan et al. used tea bags that were buried and left to rot in the soil by citizen scientists. Usually, gardens are left out of such investigations due to concerns of representativeness. They could demonstrate this within-garden effect and also discussed these results with regard to SDG target 13.3.

'Life on Land' (SDG 15) is under great pressure from human activities today, and in this context, Ferrari et al. explored in their commentary how cs can address legitimacy issues they identified in more traditional ecological monitoring approaches, which could potentially be addressed through the role of cs in data production.

In contributing to SDGs revolving around soil health, cs can play an important role for SDG 15, as Head et al. found out in their literature review. They identified 32 different methods across five indicators of soil health in cs projects, of which three were exceptionally promising ones. They concluded that cs can be a very auspicious approach to empower and support farmers all over the world to contribute to soil health and the SDGs more widely.

One unique aspect of cs projects is that they enable the establishment of partnerships ('Partnerships for the Goals', SDG 17), which is a key message in the article from Koffler et al. They identified 88 publications from cs-bee-projects from 1992 to 2020 in a systematic literature review and found that most of them were related to SDG 15 and SDG 17, although none of them was directly aligned to the SDGs. They also pointed out that many of the studies reviewed were in line with most of ECSA's principles on cs.

We would like to thank all the authors for their great work and their promising examples that show how cs can make a substantial contribution in monitoring and addressing the different SDGs and thus have a positive impact on our daily and future existence through sustainable living on this Earth. We strongly believe that the articles published in our Special Issue make an excellent contribution in demonstrating how cs can help to reach a sustainable way of life. We as editors hope that you, the reader, find these examples as compelling and inspiring as we do.

\section{List of Contributions:}

1. Heinisch, B. Knowledge translation and its interrelation with usability and accessibility. Biocultural diversity translated by means of technology and language-The case of citizen science contributing to the sustainable development goals. Sustainability 2021, 13, 54, doi:10.3390/su13010054.

2. Ajates, R.; Hager, G.; Georgiadis, P.; Coulson, S.; Woods, M.; Hemment, D. Local action with global impact: The case of the grow observatory and the sustainable development goals. Sustainability 2020, 12, 10518, doi:10.3390/su122410518. 
3. Schleicher, K.; Schmidt, C. Citizen science in Germany as research and sustainability education: Analysis of the main forms and foci and its relation to the sustainable development goals. Sustainability 2020, 12, doi:10.3390/su12156044.

4. Moczek, N.; Voigt-Heucke, S.L.; Mortega, K.G.; Fabó Cartas, C.; Knobloch, J. A SelfAssessment of European Citizen Science Projects on Their Contribution to the UN Sustainable Development Goals (SDGs). Sustainability 2021, 13, 1774, doi:10.3390/su13041774.

5. Sprinks, J.; Woods, S.M.; Parkinson, S.; Wehn, U.; Joyce, H.; Ceccaroni, L.; Gharesifard, M. Coordinator Perceptions When Assessing the Impact of Citizen Science towards Sustainable Development Goals. Sustainability 2021, 13, 2377, doi:10.3390/su13042377.

6. Kral, R.M.; Maftukhah, R.; Mentler, A.; Murtiningrum, M.; Ngadisih, N.; Keiblinger, K.M. Citizen science in the field: Co-experimentation at pilot scale for sustainable use of natural resources. Sustainability 2020, 12, doi:10.3390/su12187700.

7. Calyx, C. Sustaining citizen science beyond an emergency. Sustainability 2020, 12, 4522, doi:10.3390/su12114522.

8. Asingizwe, D.; Murindahabi, M.M.; Koenraadt, C.J.M.; Poortvliet, P.M.; van Vliet, A.J.H.; Ingabire, C.M.; Hakizimana, E.; Mutesa, L.; Takken, W.; Leeuwis, C. Co-Designing a Citizen Science Program for Malaria Control in Rwanda. Sustainability 2019, 11, 7012, doi:10.3390/su11247012.

9. Queiruga-Dios, M.Á.; López-Iñesta, E.; Diez-Ojeda, M.; Sáiz-Manzanares, M.C.; Vázquez Dorrío, J.B. Citizen Science for Scientific Literacy and the Attainment of Sustainable Development Goals in Formal Education. Sustainability 2020, 12, 4283, doi:10.3390/su12104283.

10. Bishop, I.J.; Warner, S.; van Noordwijk, T.C.G.E.; Nyoni, F.C.; Loiselle, S. Citizen science monitoring for sustainable development goal indicator 6.3.2 in England and Zambia. Sustainability 2020, 12, 10271, doi:10.3390/su122410271.

11. Wuebben, D.; Romero-Luis, J.; Gertrudix, M. Citizen science and citizen energy communities: A systematic review and potential alliances for SDGs. Sustainability 2020, 12, 10096, doi:10.3390/su122310096.

12. Filippo, D.D.; Lascurain, M.L.; Pandiella-Dominique, A.; Sanz-Casado, E. Scientometric analysis of research in energy efficiency and citizen science through projects and publications. Sustainability 2020, 12, doi:10.3390/su12125175.

13. Batsaikhan, A.; Hachinger, S.; Kurtz, W.; Heller, H.; Frank, A. Application of modern web technologies to the citizen science project BAYSICS on climate research and science communication. Sustainability 2020, 12, doi:10.3390/SU12187748.

14. Duddigan, S.; Alexander, P.D.; Shaw, L.J.; Sandén, T.; Collins, C.D. The tea bag indexUK: Using citizen/community science to investigate organic matter decomposition rates in domestic gardens. Sustainability 2020, 12, doi:10.3390/SU12176895.

15. Ferrari, C.A.; Jönsson, M.; Gebrehiwot, S.G.; Chiwona-Karltun, L.; Mark-Herbert, C.; Manuschevich, D.; Powell, N.; Do, T.; Bishop, K.; Hilding-Rydevik, T. Citizen Science as Democratic Innovation That Renews Environmental Monitoring and Assessment for the Sustainable Development Goals in Rural Areas. Sustainability 2021, 13, 2762, doi:10.3390/su13052762.

16. Head, J.S.; Crockatt, M.E.; Didarali, Z.; Woodward, M.J.; Emmett, B.A. The role of citizen science in meeting sdg targets around soil health. Sustainability 2020, 12, 10254, doi:10.3390/su122410254.

17. Koffler, S.; Barbiéri, C.; Ghilardi-Lopes, N.P.; Leocadio, J.N.; Albertini, B.; Francoy, T.M.; Saraiva, A.M. A buzz for sustainability and conservation: The growing potential of citizen science studies on bees. Sustainability 2021, 13, 959, doi:10.3390/su13020959.

Author Contributions: Conceptualization, D.D., F.H., S.F. and S.V.-H.; methodology, D.D. and F.H.; writing—original draft preparation, D.D. and F.H.; writing—review and editing, F.H., S.F. and S.V.-H. All authors have read and agreed to the published version of the manuscript.

Funding: This research received no external funding. Silke Voigt-Heucke is being funded at the Museum für Naturkunde Berlin through the Leibniz Action Plan II. 
Institutional Review Board Statement: Not applicable.

Informed Consent Statement: Not applicable.

Conflicts of Interest: The authors declare no conflict of interest.

\section{References}

1. The Science of Citizen Science; Vohland, K., Land-Zandstra, A., Ceccaroni, L., Lemmens, R., Perelló, J., Ponti, M., Samson, R., Wagenknecht, K., Eds.; Springer International Publishing: Cham, Switzerland, 2021; ISBN 978-3-030-58278-4.

2. West, S.; Pateman, R. How Could Citizen Science Support the Sustainable Development Goals? Stockholm Environment Institute: Stockholm, Sweden, 2017.

3. Fritz, S.; See, L.; Carlson, T.; Haklay, M.M.; Oliver, J.L.; Fraisl, D.; Mondardini, R.; Brocklehurst, M.; Shanley, L.A.; Schade, S.; et al. Citizen science and the United Nations Sustainable Development Goals. Nat. Sustain. 2019, 2, 922-930. [CrossRef]

4. Fraisl, D.; Campbell, J.; See, L.; Wehn, U.; Wardlaw, J.; Gold, M.; Moorthy, I.; Arias, R.; Piera, J.; Oliver, J.L.; et al. Mapping citizen science contributions to the UN sustainable development goals. Sustain. Sci. 2020,15, 1735-1751. [CrossRef]

5. Voigt-Heucke, S.; Cartas, C.F.; Mortega, K. Citizen Science SDG Conference Abstract Volume-CS-SDG Project. (Version October 2020). Available online: http:/ / doi.org/10.5281/zenodo. 4473072 (accessed on 27 January 2021). 